\title{
Communication \\ An Experiential Aged Care Module for First-Year Undergraduate Medical Students
}

\author{
Deepa Alex*, Yatinesh Kumari (D) and Amudha Kadirvelu \\ Jeffrey Cheah School of Medicine and Health Sciences, Monash University Malaysia, Bandar Sunway, \\ Subang Jaya 47500, Malaysia; yatinesh.kumari@monash.edu (Y.K.); amudha.kadirvelu@monash.edu (A.K.) \\ * Correspondence: deepa.alex@monash.edu; Tel.: +603-5514-4937
}

Citation: Alex, D.; Kumari, Y.; Kadirvelu, A. An Experiential Aged Care Module for First-Year Undergraduate Medical Students. Educ. Sci. 2021, 11, 565. https:// doi.org/10.3390/educsci11100565

Academic Editor: Douglas McHugh

Received: 16 August 2021

Accepted: 17 September 2021

Published: 22 September 2021

Publisher's Note: MDPI stays neutral with regard to jurisdictional claims in published maps and institutional affiliations.

Copyright: (C) 2021 by the authors Licensee MDPI, Basel, Switzerland. This article is an open access article distributed under the terms and conditions of the Creative Commons Attribution (CC BY) license (https:// creativecommons.org/licenses/by/ $4.0 /)$.

\begin{abstract}
A rapid demographic transition to aging populations is imminent over the next decade, especially in Southeast Asian countries. An aging population presents a host of medical challenges, such as multimorbidity; chronic illnesses; and geriatric syndromes, such as frailty, falls, dementia, and incontinence. In order to tackle such issues efficiently, there is an urgent need to train future doctors in geriatric medicine. Aged care is a specialty in medicine that was not traditionally part of the undergraduate medical curriculum. With the changing demographic, aged care content needs to be integrated into the existing curriculum for undergraduate medical students. In this paper, we present an introductory novice level geriatric module that was developed for first-year medical undergraduate students in Monash University, Malaysia. The module consisted of collaborative active learning sessions on healthy aging, interaction with older adults from the community, and a simulated experiential activity. Feedback was collected from students on module completion. The immediate impact of the module was positive from the student responses. The findings from this study will be useful to inform the development and implementation of future educational interventions for aged care, as well as to support the establishment of a vertically integrated aged care curriculum, in order to prepare future doctors to provide healthcare for the ageing Asian population.
\end{abstract}

Keywords: geriatric education; undergraduate medical curriculum; Asia 3

\section{Introduction}

Population ageing is occurring worldwide at an unprecedented pace. Globally, it is estimated that people aged 60 years and older will outnumber children under the age of 10 by the year 2030 [1]. Two-thirds of the world's older population live in developing regions, and the Asia-Pacific region is the fastest-growing hub for the older segment of the population [2]. Malaysia is a multi-ethnic middle-income nation in Southeast Asia, with seven percent of the population aged 65 years and above in 2020 [3]. The current trend of a rising number of older Malaysians is concerning due to the lack of specialized healthcare for the elderly and its economic burden. It is imperative to prepare future medical practitioners to deal with this rapid demographic shift.

With population ageing, it is anticipated that older people will form an increasing percentage of general practice consultations and acute hospital admissions [4]. There is an urgent need to embed geriatric medicine in medical undergraduate curricula and allied fields so that current and future generations of healthcare professionals develop skills to competently manage older patients. Although aged care is an established specialty in the medical field, it is mostly under-represented in the traditional undergraduate medical curriculum [5]. Exposure to hospitalized elderly who are more often debilitated and/or are physically deteriorating and with cognitive impairment may lead to the development of negative ageist stereotypes among medical students [6]. According to the WHO, ageism is defined as the stereotyping, prejudice, and discrimination against people on the basis of their age [7]. When such negative attitudes exist in medical personnel, it can affect the quality of care provided to older adults. 
Geriatric training varies widely in content and timing of delivery during medical undergraduate programs across the globe. A review examining global approaches to geriatrics in medical education identified that the majority of the published evidence was from North American and European countries, while there was a lack of studies from Asia and Africa [8]. The Teaching Geriatrics in Medical Education I (TEGEME- I) study conducted by the World Health Organization in 2000 assessed how geriatric medicine was being incorporated into the medical curriculum globally [9]. Data from 36 countries showed that majority of the healthcare systems were not well prepared to deal with the challenges of an aging population, despite the rapid demographic transition that was expected over the next few decades [9]. Over the past decade, there has been a gradually expanding evidence base supporting the development of undergraduate geriatric training programs. Among Asian countries, Japan has established geriatric departments but there is a lack of emphasis on practical aspects of aged care [10]. Taiwan has included geriatric medicine as a requirement in postgraduate medical education in 2019 [11]. A national geriatric curriculum for undergraduate training was recently been introduced in Malaysia in early 2021 [12]. Singapore is one of the few countries who have established an aged care teaching component during the early years of the medical curriculum [13]. However, there is still a lack of evidence on effective geriatric curriculum models that can lead to the generation of age-friendly doctors who are capable of dealing with the challenges of the rapidly expanding Asian older population.

In this paper, we describe an introductory module for aged care that was developed for first-year medical undergraduate students in Monash University, Malaysia. The module consisted of three sessions over a period of 3 weeks, conducted as small group active learning sessions. On completion, students evaluated the module activities and its effectiveness in achieving the objectives of the session. This paper provides an overview of the module, its objectives, the individual sessions, and the feedback received from students at Monash University, Malaysia.

\section{The Program}

The novice-level geriatric module for Year One undergraduate medical students was developed with the objective of giving students a fresh perspective about the older person and ageing. Introducing an 'active old person' as opposed to the 'sick old person' to students was aimed at creating a positive influence in their attitudes and knowledge about older people. The first two sessions of the module were adapted and modified from Adelman RD et al. [14] and the third session was an aging simulation experiential exercise. The module was attended by 143 students over 3 weeks. An overview of the module, including the objectives and individual components of each session, is presented in Figure 1. The development and implementation of the module was approved by the Early Years Medical Curriculum Management Committee, Jeffrey Cheah School of Medicine and Healthy Sciences, Monash University, Malaysia.

The active learning approach was adopted to deliver the aged care module. Such an approach to learning is ideally suited to the professional context, where the integration of theory and practice is paramount. The geriatric module is a perfect fit for this kind of an approach, where a combination of core knowledge along with application of complex concepts comes into play. Active learning strategies have been shown to improve engagement and promote self-directed learning, while allowing better knowledge retention [15]. One of the main objectives of this module was to encourage positive attitudes toward aging among future medical doctors. In order to achieve a longstanding impact on attitudes and practices, there needs to be exposure to geriatric content that is appropriate for the students' level of learning and horizontally integrated with other subjects during the same period. The content and timing of these sessions were designed such that it integrated well with the concurrent disciplines that were delivered during the same period of learning. This would enable students to make cross disciplinary connections and allow better knowledge assimilation and retention. As this was the first time students were exposed to the geriatric 
content, the module was focused on core topics of communication, ageism, and common physiological changes seen with aging. The sessions were designed to be engaging and to generate more interest in the topic rather than be content heavy.

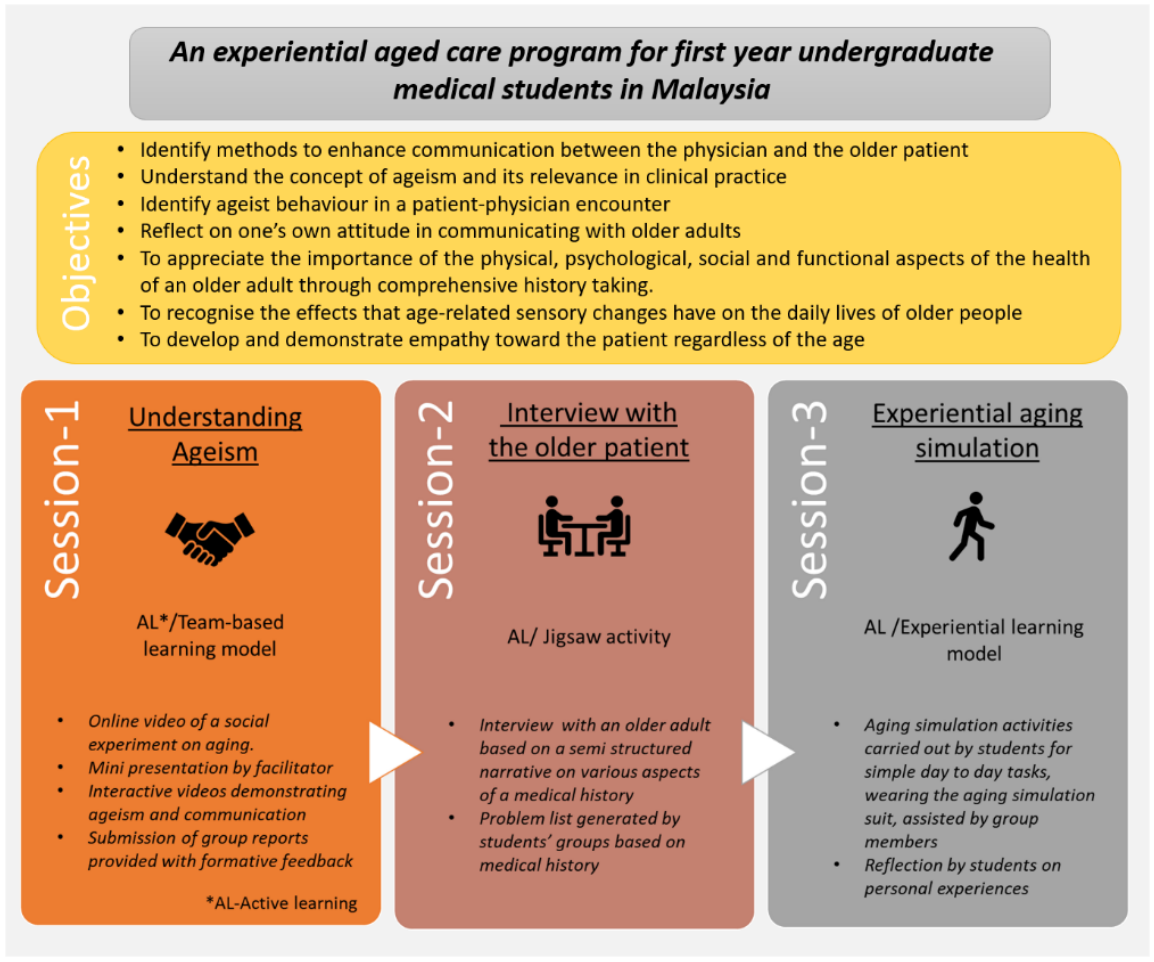

Figure 1. Overview of the program.

\section{Session 1: Understanding ageism}

Communication is considered a fundamental clinical skill to establish a relationship with the patient, paving the way to successful diagnosis and treatment. The first session was designed for students to appreciate how ageism can commonly occur in a medical consult. Students viewed an online video on a social experiment on disrupting stereotypes on aging, as a pre-learning activity. At the beginning of the session, students were given a mini presentation on the topic by a geriatrician, after which they viewed recorded videos of medical encounters between practitioners and older patients. This session highlighted that ageism could be hidden in the subtle aspects of communication. Two scripted encounters were created by the teaching faculty for this session. The interactive videos showcased two clinical encounters of the same patient with different communication styles used by the clinician, one of which highlighted ageism in a medical encounter, while the other portrayed an age-friendly clinician. Questions on various aspects of communication and ageism were embedded throughout the video to trigger brainstorming. This then led onto group discussions by student groups on the differences between the communication styles shown in the videos, based on verbal and non-verbal cues. Group reports on the medical encounters were submitted by students as a post learning activity for which formative feedback was provided.

For the first session, we adopted a modified version of the team-based learning model. In this approach, there is a pre-learning segment followed by a classroom portion where learners are tested on the pre-class material and then challenged to apply core content to scenarios as a team [16]. For the in-class activity, students were shown multiple video clips of medical encounters between doctors and patients. They then had to do analysis in small groups and present their finding to the whole class as teams. This session also applied the 'muddiest point' model [17] by using interactive videos, which prompted students with 
questions at various points throughout the exercise in order to encourage brainstorming and clear up areas of potential ambiguity.

\section{Session 2: Interview with the older patient}

The second session had two older adults from the community interacting with students in the active learning session, as a large group activity. The older persons engaged with student representatives from each group, while this was observed by the rest of the class. Their interaction was based on a semi- structured dialogue, during which various aspects of medical history were collected. This was followed by group discussion among students in their own groups, to put together a problem list, based on history provided. This activity enabled students to peer teach and learn from one another. Older adults with a positive attitude and willingness to share experiences were handpicked by the facilitators in order to expose students to active older people. At the end of the session, clinical findings for the case were provided and students had to list out the multiple issues in the case. The cases were designed such that the social and functional aspects of the history were relevant in putting together a problem list. Students worked together in groups to solve the various aspects of the case just as in a jigsaw puzzle, while also getting the opportunity to interact with older adults in a semi-formal atmosphere.

The second session saw older adults interacting with students in a large group setting. The jigsaw model [18] of active learning was applied for this particular session. Each team of students were given a different aspect of clinical history to collect from the patient. A clinical examination video relevant to the case was shown to the students. At the end of the session, each team generated a problem list for the patient. The problem list was akin to the jigsaw puzzle to be solved through the various bits of history collected. The two cases used for the simulated patients were created on a background of neurological and musculoskeletal systems, which was being concurrently dealt with in their other classes during that period. This enabled horizontal integration with other relevant teaching units. The older adults for these sessions were chosen after careful consideration in order to expose students to actively aging adults in the community and to disrupt any negative ageist stereotypes.

\section{Session 3: Aging simulation}

The final session was an experiential aging simulation exercise aimed to get the students to relate to the practical challenges faced by older adults in their everyday life. Low-fidelity aging simulation suits were worn by students in this session. The suit was designed by academics to simulate common sensory changes seen with aging, such as visual and hearing impairments, joint issues like limited mobility, and nerve deficits such as numbness, while carrying out simple day to day activities such as using the hand phone, climbing stairs, etc. Students shared personal views and opinions based on their in-class experience as an intergroup activity. There was a gradual shift from feedback provided by the tutors and the patient in the first two sessions, to student-generated feedback and self-reflection by the end of the module.

The third and final session on aging simulation was purely based on the experiential learning model. This approach has been used successfully to sensitize healthcare professionals to the needs of older people [19]. For first-year medical students who are concurrently learning basic sciences such as physiology and pathology, this session enables them to connect their in-class experience with their basic science concepts, allowing improved retention and a deeper understanding of concepts. Moreover, this approach coupled with the exposure to older adults who lead active lifestyles in the previous session would hopefully have a positive and long-lasting influence on students' attitudes and future practice. In total, 40 innovative low-fidelity simulation suits were designed for this session using low-cost and locally sourced materials. 


\section{Feedback}

Student feedback to the sessions was captured following completion of the module and the impact of the module on the students was strongly reflected in their responses. Out of a total of 143 students, 106 students $(74.1 \%)$ provided feedback for the module. Among students who responded, $99 \%$ felt that the geriatric module enhanced their learning experience, while $98.1 \%$ felt that the objectives of the module were achieved. Figures $2-4$ depict student feedback for individual sessions of the geriatric module. Tables 1 and 2 show examples of open-ended responses to questions in the feedback survey.

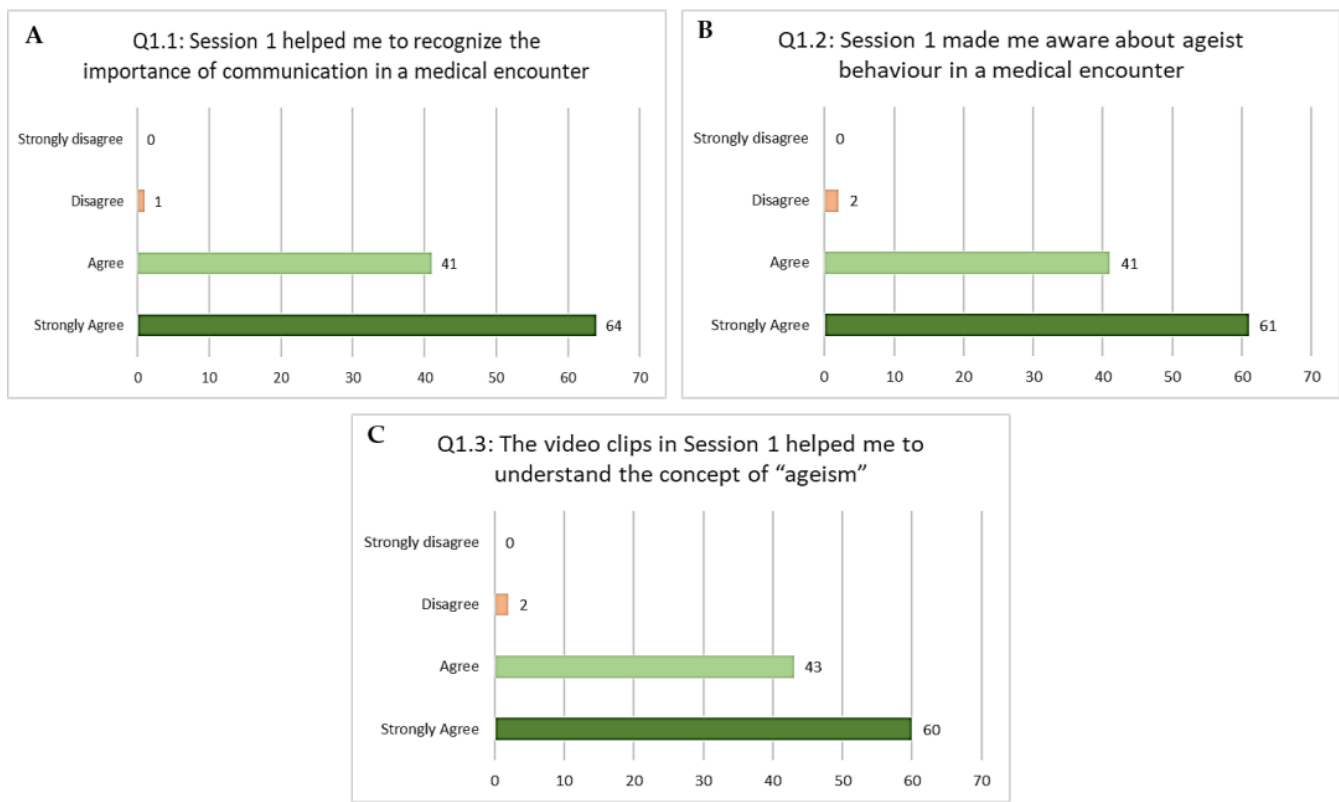

Figure 2. Session 1-Understanding ageism, (A-C) represent the students' responses.

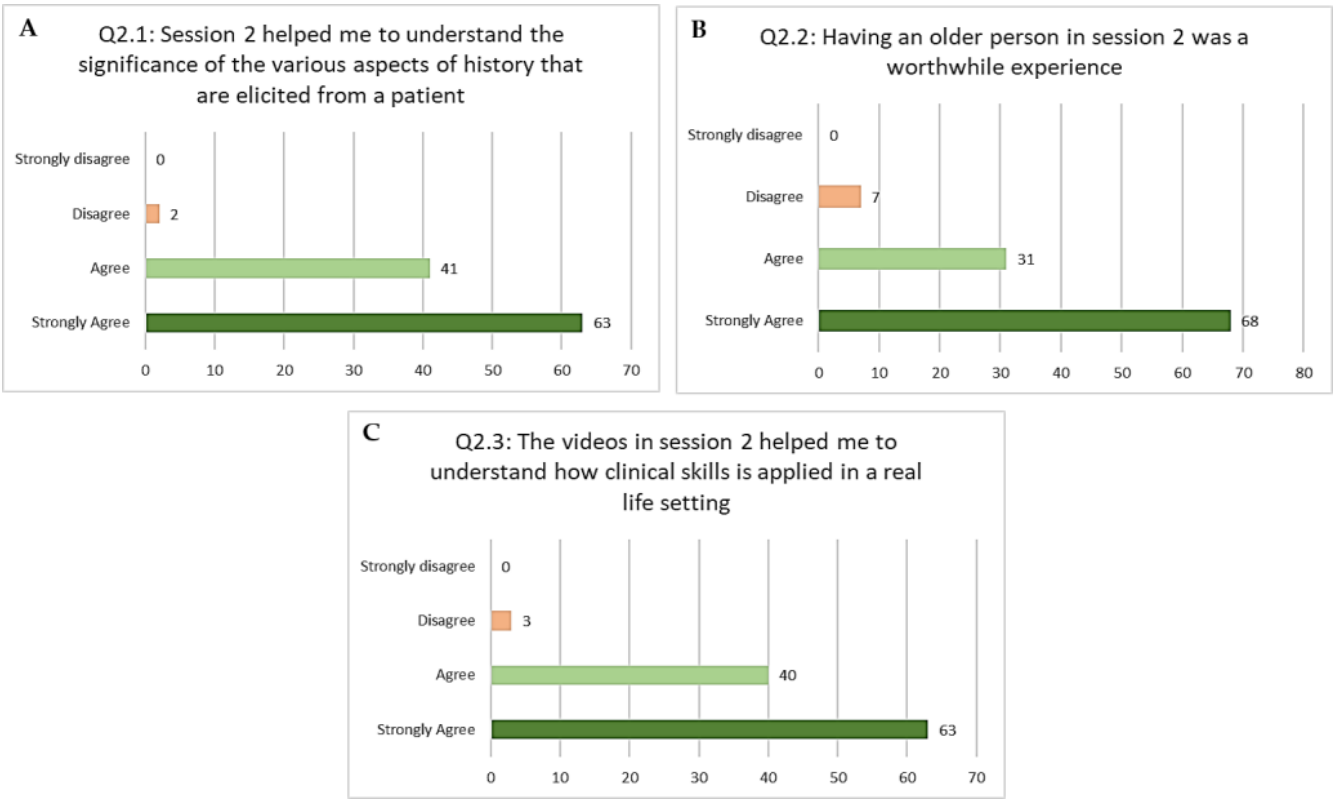

Figure 3. Session 2-Interview with an older adult, (A-C) represent the students' responses. 


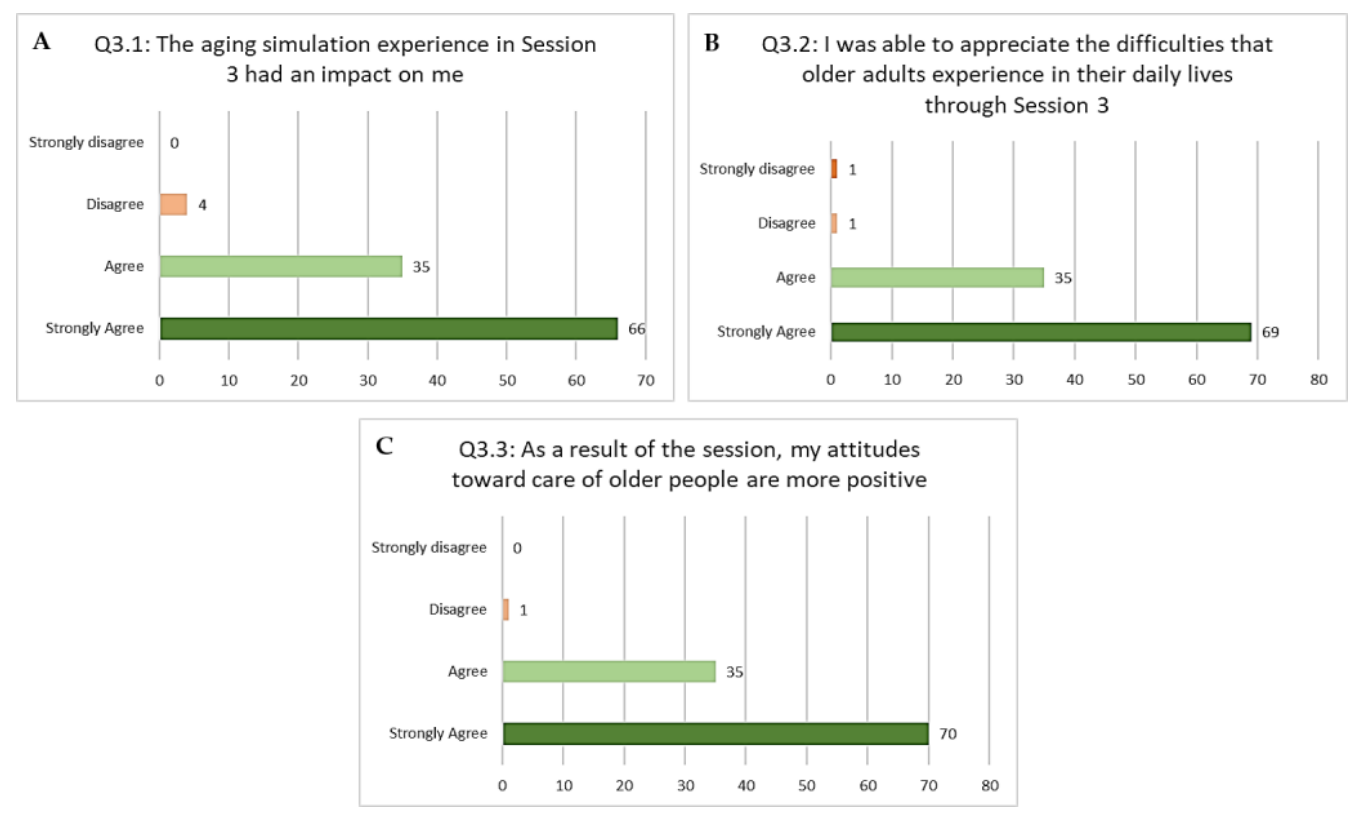

Figure 4. Session 3-Ageing simulation, (A-C) represent the students' responses.

Active learning strategies have been shown to be effective in the delivery of geriatric teaching [20]. Methods, including team-based learning [21] and experiential learning [22], have been shown to improve student engagement when compared to traditional lecturebased teaching. This is especially relevant for geriatric medicine as a subject, where there is evidence to suggest that there are low levels of interest and lack of knowledge about aged care among medical students [23]. One of the main objectives of the geriatric module described in this paper is to dispel negative stereotypes among medical students at an early stage of their undergraduate training by giving them opportunities to actively engage with older adults, brainstorm among peers, as well as participate in simulation activities. Although simulation has been shown, in some cases, to worsen attitudes [24], we believe this can be attributed to exposing students to an aging simulation without providing an initial knowledge base of the subject. A future action would be to evaluate whether this geriatric curricular model is effective in bringing about long-term changes in the perceptions of medical students towards aging.

Table 1. Responses to the question: Which part of the session was most useful to you and why?

Question
Excerpts from Students' Feedback
"The very first session, because I never thought about the elderly
and their health deeply. This session opened my eyes".
"Session 1 helped me to realize how important verbal and
non-verbal cues are, when it comes to taking a medical history."
"Interviewing an older person made me realize that they have
different needs compared to the general population"
$\begin{gathered}\text { "Shich part of the session } \\ \text { was most useful to you } \\ \text { and why? }\end{gathered}$
$\begin{gathered}\text { "Seople communicate and how the different parts of history play } \\ \text { an integral role in managing the patient as a whole" }\end{gathered}$
"When I wore the suit, I wanted to do everything by myself. I can
see how you need to respect the independence of the older
individual and not just do everything for them"
"Going up and down the stairs was very difficult. It reminded me
of my grandma who has arthritis."


Table 2. Responses to the question: How did this curricular exposure influence you?

\begin{tabular}{c} 
Question \\
\hline \\
"I feel that I can better empathise and relate to the elderly better \\
after the sessions. I found it difficult to understand why the \\
elderly had constant aches and pains but now I feel that I will be \\
able to address their concerns in a better way. I would like to \\
thank the doctors for giving us this learning opportunity." \\
"It made me more empathetic towards older people and realise \\
how much they have to go through on a daily basis." \\
"I feel that people often assume that an old person is exaggerating \\
their complaints. However, after these sessions, I am truly able to \\
feel the frustration and helplessness elderly feel on a daily basis." \\
"It reminded me that we are going to be dealing with an ageing \\
population and these 3 sessions helped me realise that we need to \\
equip ourselves well for future encounters with the elderly." \\
"It gave me a very good experience and taught me to look at \\
medicine, life and the elderly in a new angle. I appreciate the \\
effort and this module as it gives us a more hands on experience \\
to aid what we will face in the future.
\end{tabular}

\section{Conclusions}

The novice-level geriatric module is a major step to a broader vision for geriatric education in Asia. We are one of the few schools in the region to have an aged care module as part of the early years medical curriculum [11]. The immediate impact of the aged care module on medical students was found to be positive. With the rapidly advancing demographic transition to an aging population, it is critical for pedagogies to evolve accordingly. Geriatric education is an established area in developed countries but has a far way to go in Southeast Asia, where geriatric services are still at their infancy but rapidly progressing. Newer approaches will be needed to prepare future medical practitioners to deal with the challenges of an aging population. Geriatric teaching is best integrated into relevant parts of the curriculum at various stages. Introductory concepts can be provided through such a program as described, or with locally contextualized variations. This can lay a firm foundation for students to build on knowledge and skills in their formal aged care postings in their senior undergraduate clinical years. Future studies on geriatric curriculum and assessment are needed to identify teaching models that are best suited to prepare future doctors to deal with the aging population.

Author Contributions: Conceptualization, D.A, A.K. and Y.K.; writing-original draft preparation, D.A. and Y.K.; writing - review and editing, A.K.; project administration, D.A., Y.K. and A.K.; funding acquisition, D.A. All authors have read and agreed to the published version of the manuscript.

Funding: This study was funded by Monash University Malaysia's School Collaborative Grant 2021 (SED-000059) and Jeffery Cheah School of Medicine and Health Sciences.

Institutional Review Board Statement: The data and student feedback presented in this paper were collected as part of "new educational activity implementation and evaluation" to assess the effectiveness in achieving the learning objectives of the module. Student participation in the module evaluation was voluntary. Approval for the aged care module implementation was sought from the Monash University Medicine Early Years Management Committee.

Data Availability Statement: The datasets presented in this article are not readily available due to concerns about loss of fidelity of personally identifiable data, the dataset is currently not available publicly. However, the dataset will be released anonymized through written requests submitted to the corresponding author. Requests to access the datasets should be directed to Deepa Alex, deepa.alex@monash.edu.

Conflicts of Interest: The authors declare no conflict of interest. 


\section{References}

1. Population Division, Department of Economic and Social Affairs, United Nations. World Population Ageing 2017-Highlights (ST/ESA/SER.A/397); United Nations: New York, NY, USA, 2017.

2. UNFPA Asia-Pacific Regional Office (APRO). Addressing Population Ageing in Asia and the Pacific Region: A Life-Cycle Approach; UNFPA: Bangkok, Thailand, 2021.

3. Department of Statistics Malaysia. Current Population Estimates; Department of Statistics Malaysia: Putrajaya, Malaysia, 2020.

4. Van den Heede, K.; Bouckaert, N.; Van de Voorde, C. The impact of an ageing population on the required hospital capacity: Results from forecast analysis on administrative data. Eur. Geriatr. Med. 2019, 10, 697-705. [CrossRef]

5. Sallehuddin, H.; Tan, M.P.; Blundell, A.; Gordon, A.; Masud, T. A national survey on the teaching provision of undergraduate geriatric medicine in Malaysia. Gerontol. Geriatr. Educ. 2021, 1-12. [CrossRef] [PubMed]

6. De Biasio, J.C.; Parkas, V.; Soriano, R.P. Longitudinal assessment of medical student attitudes toward older people. Med. Teach. 2016, 38, 823-828. [CrossRef] [PubMed]

7. São José, J.M.S.; Amado, C.A.F.; Ilinca, S.; Buttigieg, S.C.; Taghizadeh Larsson, A. Ageism in health care: A systematic review of operational definitions and inductive conceptualizations. Gerontologist 2019, 59, e98-e108. [CrossRef] [PubMed]

8. Mateos-Nozal, J.; Beard, J.R. Global approaches to geriatrics in medical education. Eur. Geriatr. Med. 2011, 2, 87-92. [CrossRef]

9. Keller, I.; Makipaa, A.; Kalenscher, T.; Kalache, A. Global Survey on Geriatrics in the Medical Curriculum: A Collaborative Study of WHO and the International Federation of Medical Students' Association; World Health Organization: Geneva, Switzerland, 2002.

10. Arai, H. Geriatrics in the most aged country, Japan. Arch. Gerontol. Geriatr. 2009, 49, S1-S2. [CrossRef]

11. Chen, L.-K. Geriatric medical education in rapidly aging Asia. Aging Med. Healthc. 2020, 11, 72-73. [CrossRef]

12. Sallehuddin, H.; Tan, M.P.; Blundell, A.; Gordon, A.L.; Masud, T. Development of a Malaysian undergraduate geriatric medicine curriculum. Aging Med. Healthc. 2020, 11, 82-88. [CrossRef]

13. Koh, G.C.; Merchant, R.A.; Lim, W.S.; Amin, Z. The knowledge-attitude dissociation in geriatric education: Can it be overcome? Ann. Acad. Med. Singap. 2012, 41, 383.

14. Adelman, R.D.; Capello, C.F.; LoFaso, V.; Greene, M.G.; Konopasek, L.; Marzuk, P.M. Introduction to the older patient: A "first exposure" to geriatrics for medical students. J. Am. Geriatr. Soc. 2007, 55, 1445-1450. [CrossRef]

15. Wolff, M.; Wagner, M.J.; Poznanski, S.; Schiller, J.; Santen, S. Not another boring lecture: Engaging learners with active learning techniques. J. Emerg. Med. 2015, 48, 85-93. [CrossRef]

16. Chen, M.; Ni, C.; Hu, Y.; Wang, M.; Liu, L.; Ji, X.; Chu, H.; Wu, W.; Lu, C.; Wang, S. Meta-analysis on the effectiveness of team-based learning on medical education in China. BMC Med. Educ. 2018, 18, 1-11. [CrossRef] [PubMed]

17. Moffett, J. Twelve tips for "flipping" the classroom. Med. Teach. 2015, 37, 331-336. [CrossRef] [PubMed]

18. Bhandari, B.; Mehta, B.; Mavai, M.; Singh, Y.R.; Singhal, A. Medical education/original article jigsaw method: An innovative way of cooperative learning in physiology. Indian J. Physiol. Pharm. 2017, 61, 315-321.

19. Gugliucci, M.R.; Weiner, A. Learning by living: Life-altering medical education through nursing home-based experiential learning. Gerontol. Geriatr. Educ. 2013, 34, 60-77. [CrossRef] [PubMed]

20. Lucchetti, A.L.; Duarte, B.S.; de Assis, T.V.; Laurindo, B.O.; Lucchetti, G. Is it possible to teach Geriatric Medicine in a stimulating way? Measuring the effect of active learning activities in Brazilian medical students. Australas. J. Ageing 2019, 38, e58-e66. [CrossRef] [PubMed]

21. Punja, D.; Kalludi, S.N.; Pai, K.M.; Rao, R.K.; Dhar, M. Team-based learning as a teaching strategy for first-year medical students. Australas. Med. J. 2014, 7, 490. [CrossRef] [PubMed]

22. Correia, R.H.; Klea, L.; Campbell, G.; Costa, A.P. Fostering intergenerational education: An experiential learning program for medical students and older adults. Can. Med. Educ. J. 2020, 11, e74. [CrossRef] [PubMed]

23. Fitzgerald, J.T.; Wray, L.A.; Halter, J.B.; Williams, B.C.; Supiano, M.A. Relating medical students' knowledge, attitudes, and experience to an interest in geriatric medicine. Gerontologist 2003, 43, 849-855. [CrossRef] [PubMed]

24. Lucchetti, A.L.G.; Lucchetti, G.; de Oliveira, I.N.; Moreira-Almeida, A.; da Silva Ezequiel, O. Experiencing aging or demystifying myths?-Impact of different "geriatrics and gerontology" teaching strategies in first year medical students. BMC Med. Educ. 2017, $17,1-9$. 